Old Dominion University

ODU Digital Commons

Bioelectrics Publications

Frank Reidy Research Center for Bioelectrics

2011

\title{
Nanosecond Pulse Electrical Fields Used in Conjunction with Multi-Wall Carbon Nanotubes as a Potential Tumor Treatment
}

\author{
Michael W. Stacey \\ Christopher Osgood \\ Old Dominion University \\ Bhargava Subhash Kalluri \\ Old Dominion University \\ Wei Cao \\ Old Dominion University \\ Hani Elsayed-Ali \\ Old Dominion University \\ See next page for additional authors
}

Old Dominion University,mstacey@odu.edu

Follow this and additional works at: https://digitalcommons.odu.edu/bioelectrics_pubs

Part of the Biomedical Engineering and Bioengineering Commons, Cell and Developmental Biology Commons, and the Nanotechnology Commons

\section{Repository Citation}

Stacey, Michael W.; Osgood, Christopher; Kalluri, Bhargava Subhash; Cao, Wei; Elsayed-Ali, Hani; and Abdel-Fattah, Tarek, "Nanosecond Pulse Electrical Fields Used in Conjunction with Multi-Wall Carbon Nanotubes as a Potential Tumor Treatment" (2011). Bioelectrics Publications. 70.

https://digitalcommons.odu.edu/bioelectrics_pubs/70

This Article is brought to you for free and open access by the Frank Reidy Research Center for Bioelectrics at ODU Digital Commons. It has been accepted for inclusion in Bioelectrics Publications by an authorized administrator of ODU Digital Commons. For more information, please contact digitalcommons@odu.edu. 
Authors

Michael W. Stacey, Christopher Osgood, Bhargava Subhash Kalluri, Wei Cao, Hani Elsayed-Ali, and Tarek Abdel-Fattah 


\title{
Nanosecond pulse electrical fields used in conjunction with multi-wall carbon nanotubes (MWCNTs) as a potential tumor treatment.
}

Michael Stacey ${ }^{1}$, Christopher Osgood ${ }^{1}$, Bhargava Subhash Kalluri ${ }^{1}$, Wei Cao ${ }^{2}$, Hani Elsayed$\mathrm{Ali}^{2}$ and Tarek Abdel-Fattah ${ }^{3,4}$

${ }^{1}$ Frank Reidy Research Center for Bioelectrics, Old Dominion University, 4211 Monarch Way, Norfolk, VA 23508 USA

${ }^{2}$ Applied Research Center and Department of Electrical and Computer Engineering, Old Dominion University, Norfolk, VA 23529 USA

${ }^{3}$ Applied Research Center and Department of Biology, Chemistry and Environmental Science, Christopher Newport University, Newport News, VA 23606 USA

${ }^{4}$ Corresponding Author: fattah@cnu.edu

\begin{abstract}
The objectives of this article were to fabricate pure samples of multi-walled carbon nanotubes (MWCNTs) and to determine their toxicity in tumor cell lines. MWCNTs were dispersed in a concentration of the surfactant T80 that was minimally toxic. Cell-type variation in toxicity to MWCNTs was observed but was not significantly different to unexposed controls. Additionally, we investigated increased cell killing of the pancreatic cancer cell line PANC1 when exposed to ultrashort (nanosecond) pulsed electrical fields (nsPEF) in the presence of MWCNTs as a potential form of cancer therapy. We hypothesized that the unique electronic properties of MWCNTs disrupt cell function, leading to cell death, when cells are exposed to nsPEF. We observed a 2.3-fold reduction in cell survival in cells pulsed in the presence of MWCNTs compared to pulsed controls. This study demonstrates that ultrashort pulse electrical field applications have enhanced killing effects when cells are previously grown in the presence of MWCNTs, suggesting that the electrical properties of MWCNTs play a vital role in this process and is suggestive of a synergistic interaction between these nanomaterials and electrical fields.
\end{abstract}




\section{Introduction}

Carbon nanotubes (CNTs) are a novel carbon allotrope that possesses structural and electronic properties that are unique from other carbon allotropes, such as graphite, fullerene, and diamond [1]. Based on their unique electronic, mechanical and chemical properties, nanotubes have been used in many applications, such as advanced scanning probes [2], electron field emission sources [3], hydrogen storage materials [4], and building blocks of molecular electronics [5,6]. CNTs have highly $\pi$-conjunctive and hydrophobic sidewalls consisting of sp2 carbons [7], which enable them to interact with the biological structures within the cell level [8]. As a result, CNTs have been used in many biochemical applications, such as enzymatic films [9], nanostructured medical devices, such as tissue-engineered scaffolds [8] and constructs for intracellular drug/gene delivery $[10,11]$. CNTs that come into contact with bacterial cells also induce damage at the plasma membrane [12].

The use of electrical fields in biology has yielded knowledge on the responses of cellular components to electrical fields that are dependent upon the length of exposure and electrical field intensity. Electroporation is perhaps one of the best recognized cellular responses to electrical fields, where electrical applications in the order of millisecond to microsecond and electrical field intensities in the order of $1 \mathrm{kV} / \mathrm{cm}$ induce pore formation in the outer cell membrane, allowing for the transit of xenomolecules into the cell [13]. We have recently begun characterizing the biological effects of ultrashort (nanosecond), pulsed electrical fields (nsPEF) on human cells. nsPEF utilizes pulses in the order of 10-300 ns with rapid rise times and electrical field strengths up to $350 \mathrm{kV} / \mathrm{cm}$. As the pulse duration shortens, there is a lower incidence of electrical field interactions that modify the outer plasma membrane and a higher incidence of electrical field interactions that modify intracellular structures $[14,15]$; and because the pulse duration is short, there are no significant thermal effects. With pulses that have sharp rise times, and durations that are short compared to the charging time of the cell membrane, the field penetrates throughout the cell, charging internal structures, creating distinct intra-cellular effects (Figure 1).

The recent applications of nsPEFs to human cell lines are increasing our knowledge of the biological effects of exposed cells and include the induction of apoptosis [16], the breakdown of lysosome membranes [17] and calcium bursts [18,19]. Cell-type specific differences in nsPEF exposed cells have been observed and include differences in cell survival, DNA damage, and cell 
cycle parameters [20] as well as membrane potential [21] and mitochondria-mediated induction of caspase activation [16]. Cell-type specific responses to nsPEFs are well documented but not fully understood.

The unique structural and electronic properties of multi-walled carbon nanotubes (MWCNTs), due to their large length-to-diameter ratio and a good conductivity, make it possible to form a three-dimensional conducting matrix within or adjacent to cancer cells that allow electrical conductance, possibly disrupting cell function leading to cell death. Targeting MWCNTs specifically to cancer cells and exposing the cells to high intensity electrical fields

offer a potential novel form of cancer treatment. In this study, we correlate the survivability after treating three cancer cell lines with MWCNTs along with application of pulsed electrical fields. Our objectives are 1) fabricate a pure sample of MWCNTs and to use these to 2) determine their toxicity in three different tumor cell lines. As a means of utilizing the electrical properties of MWCNTs, we present preliminary data investigating the effects of pulsed electrical fields on cell survival when exposed in the presence of MWCNTs.

\section{Materials and Methods}

MWCNTs fabrication

The catalytic decomposition of methane on iron-based catalysts was used for the MWCNTs growth [22]. The reaction took place in a quartz tube. Under an argon flow, the furnace was heated to the reaction temperature of $950{ }^{\circ} \mathrm{C}$. In the step of catalyst reduction (10 min.), argon was replaced by hydrogen $\left(1000 \mathrm{~cm}^{3} / \mathrm{min}\right.$.). In the growth process, methane replaced the hydrogen flow. The reactor was then cooled to ambient temperature under argon flow. The MWCNTs were purified by refluxing the MWCNTs in $2.0 \mathrm{M}$ nitric acid for $5 \mathrm{~h}$, followed by centrifugation, filtration, and drying under vacuum at $100^{\circ} \mathrm{C}$. The MWCNTs were dispersed in ethanol for preparing specimens suitable for TEM observation. The TEM specimens were prepared by drying droplets of the MWCNT dispersion on carbon-coated Cu grids. The high resolution transmission electron microscopy (HRTEM) characterization was then carried out on a JEM-2100F (JEOL, Japan) microscope at $200 \mathrm{kV}$. Powdered MWCNTs were suspended in Millipore water containing $0.002 \%$ polyoxyethylene sorbitan monooleate (Tween 80 Sigma P4780) surfactant to a final concentration of $250 \mu \mathrm{g} / \mathrm{ml}$ [23]. The CNT dispersion was sonicated for 2x15mins in a L\&R Ultrasonics PC3 water bath sonicator and left overnight at room temperature. Agglomerates were pelleted by centrifugation at 3,000 rpm for 5 min. (Eppendorf 
5810R) and the supernatant gently removed and sonicated further for 2x15 min. The solution was centrifuged at 10,000 rpm on a desktop ultracentrifuge and the CNT suspension removed for experiments. The purity of the MWCNT fabrication was determined by high resolution transmission electron microscopy (TEM) and by energy dispersive spectroscopy (EDS) using an Oxford INCAx-sight EDS detector (Concord, MA) attached to the HRTEM. Thermogravimetric analysis (TGA) was conducted using a TA instruments Q500 thermogravimetric balance, working in high-resolution dynamic mode in the temperature range from 25 to $800{ }^{\circ} \mathrm{C}$. In the TGA experiment, the sample was maintained in a flow of dry air at $60 \mathrm{sccm}$.

\section{Cell culture}

The human pancreatic cancer cell line PANC1, the human uterine carcinoma line HeLa, and a mouse melanoma cell line B16 were grown in DMEM growth medium supplemented with 10\% fetal bovine serum, $2 \mathrm{mM}$ L-Glutamine, and 1\% penicillin and streptomycin. Cell cultures were grown at $37^{\circ} \mathrm{C}$ in a humidified incubator with $5 \% \mathrm{CO}_{2}$ atmosphere.

Determination of toxicity of the surfactant $T 80$

Concentrations of T80 from $0.002 \%-1 \%$ were made in growth medium and cells incubated for 72 hours in a 96 well plate. Cell viability was measured by the MTT assay following the manufacturer's guidelines (Roche Applied Science, Mannheim, Germany).

Determination of toxicity of MWCNTS

When cultures were approximately $75 \%$ confluent, cells were removed by trypsinization and $10^{5}$ cells per $5 \mathrm{ml}$ were seeded into tissue culture wells. $500 \mu \mathrm{l}$ of growth medium was added to control flasks, $500 \mu \mathrm{l}$ of Tween 80 surfactant (0.002\%) added to a second control flask and 500 $\mu \mathrm{l}$ of prepared MWCNTs (approximately $23 \mu \mathrm{g} / \mathrm{ml}$ final concentration) added to the final flask and the cells incubated for 48 hours. All cells were used between passages 4-8.

The rate of growth of cells can be determined by measuring increased cell number per unit time of a given cell population, which is determined by the length of time of the cell cycle [24]. When a cell population is exposed to potentially harmful reagents, the length of the cell cycle increases as cells respond to and repair induced damage, resulting in a relative decrease in cell number per unit time compared to untreated controls. To determine growth characteristics of cells exposed to MWCNTs, and hence the potentially harmful effects of MWCNTs, changes in relative cell number per unit time were determined for each cell line and compared to unexposed 
controls. Changes in cell numbers were determined from $\ln (\mathrm{N} / \mathrm{No}) / \mathrm{t}$ where No $=$ initial cell number, $\mathrm{N}=$ final cell number, and $\mathrm{t}=$ time in hours between No and $\mathrm{N}$.

Cell viability of PANC1 cells when exposed to nsPEF

To determine the viability of PANC1 cells exposed to nsPEF in the presence of MWCNTs, cells were pretreated with MWNT/T80, and then exposed to nsPEFs. nsPEF applications are known to penetrate and affect internal cellular structures [25]; and due to their electrical properties, the presence of MWCNTs may enhance the killing effects of such pulses. Cells were removed from tissue culture flasks by trypsinization and their concentration adjusted to $10^{6} / \mathrm{ml}$. $140 \mu \mathrm{l}\left(1.4 \times 10^{5}\right.$ cells) were loaded into a $1 \mathrm{~mm}$ width electroporation cuvette (BioRad, CA USA ) and placed in a 300 ns pulsed electrical field applicator as described previously [20]. Eight pulses were applied at a repetition rate of $\sim 1 \mathrm{~Hz}$ and the electrical field produced in the electroporation cuvette was approximately $50 \mathrm{kV} / \mathrm{cm} /$ pulse. Trypan blue is a vital dye that stains dead cells blue while leaving live cells clear. Following treatment, cells were mixed with an equal volume of trypan blue and $10 \mu$ l loaded onto a hemacytometer and the number of live (unstained) and dead (stained) cells counted. Cell viability is determined as the number of live cells/total cell number x100\%.

\section{Statistical analysis}

Statistical significance was determined by Student's t-test, with values of $\mathrm{p}<0.05$ considered significant.

\section{Results and Discussion}

\section{Purity of MWCNTS}

We initially examined the purity of fabricated MWCNTs by energy dispersive spectroscopy (EDS) connected to a transmission electron microscope (TEM). The EDS spectra acquired from bundled MWCNTs and an opening area on the TEM grid are shown in (Figure 2.). The results indicate pure carbon nanotubes with no contamination on the surfaces (the $\mathrm{Cu}$ peak is from the supporting grid and specimen holder). From the TEM analysis and the corresponding EDS, a non-uniformly distributed small amount of $\mathrm{Ni}$ and $\mathrm{Fe}$ (in the form of nanoparticles embedded in a very small fraction of the MWCNTs, most likely from the fabrication process) were detected. The average weight percentages of all contaminants were less than $1 \%$. Also, TGA analysis was used to investigate the purity of MWCNTs. In the TGA experiment, all the carbon is assumed 
converted to $\mathrm{CO} / \mathrm{CO} 2$, and any metal present is converted to an oxide. With increasing $T$, carbon is converted to $\mathrm{CO} / \mathrm{CO} 2$ and mass or mass \% $(\mathrm{m})$ decreases, Figure 3a. Characteristic combustion temperatures of various carbon phases in the soot, e.g., amorphous carbon, CNT, can be identified by the peak positions in the derivative data (DTG), i.e., - $\mathrm{d} m / \mathrm{d} T$ vs $T$ data, Figure 3b. The positions of the resultant peaks can be affected by the amount of residual catalyst in the sample and the carbon allotropy (amorphous and/or nanotubes) [26-29]. Increasing metal catalysts residue tends to shift the DTG peaks to lower temperature, i.e., the growth catalyst also acts as an oxidation catalyst and lowers the combustion temperature. The reported oxidation temperature of the amorphous carbon is about $350{ }^{\circ} \mathrm{C}$ and for carbon nanotubes is about $480{ }^{\circ} \mathrm{C}$ in the presence of residual catalysts [26-29]. Figure 3 shows the TGA and DTGA results of the MWCNTs used in this study. The single DTG peak at $480{ }^{\circ} \mathrm{C}$, Figure $3 \mathrm{~b}$, indicates one type of carbon present in the sample which is related to carbon nanotubes i.e. free from amorphous carbon. The average weight percentages of the residuals, Figure 3a, were less than $2 \%$.

\section{Toxicity of the surfactant T80}

T80 is an effective surfactant that has been used as an emulsifier and dispersing agent for medications, however, concentrations of between $1 \%$ and $5 \%$ have been shown to cause abnormal reproductive development when injected into rats [30]. Due to potential adverse sideeffects, the toxicity of T80 used must be considered for the dispersion of MWCNTs. To determine a concentration of T80 that would be minimally toxic, we grew PANC1 cells in the presence of various concentrations of T80. Figure 4 shows that concentrations $>0.2 \%$ show decreased viability. Based on these observations, we performed experiments in $0.002 \%$ T80. Toxicity of MWCNTS

Fabricated MWCNT preparations yielded a pure sample, indicating that our observations are unlikely to be due to contaminants. We exposed exponentially growing cells to $\sim 23 \mu \mathrm{g} / \mathrm{ml}$ MWCNT for 48 hours and measured relative changes in cell numbers in exposed versus unexposed controls. All three cell lines exposed to MWCNTs showed a deviation of recorded cell numbers compared to controls (-8.7\%, $-36.9 \%$ and $+25.0 \%$ for B16, PANC1 and HeLa cells, respectively. Table 1); however, none of the differences were statistically significant between control and MWCNT exposed cells. This suggests that MWCNTs do not appear to disrupt the ability of the cells to progress through the cell cycle and are, therefore, not toxic under these 
conditions. There was no significant difference between controls and surfactant exposed cells, suggesting that the surfactant was not influencing observed changes in MWCNT exposed cells. There was a significant difference between cell lines in response to MWCNT exposure. PANC1 $(-36.9 \%)$ and HeLa (+25.0\%) cells were significantly different from each other ( $\mathrm{p}=0.023)$. There was no significant difference between B16 and PANC1 or HeLa cells. PANC1 cells appeared to be more sensitive to MWCNTs than HeLa or B16 cells. These cell lines are all derived from very different cancer types, and the pancreatic cancer line PANC1 may have properties that make it intrinsically more sensitive to MWCNTs. The MWCNT may be packaged intracellularly in PANC1 cells such that the ability to grow and proliferate is diminished. Alternatively, the inhibitory effects may be affected by MWCNTs that are external to the cells.

Cell viability of PANC1 cells when exposed to nsPEF

The current-carrying capacity of carbon nanotubes has been reported to be 1,000 times higher than copper wires [31]. CNT dispersions exposed to an electrical field have 100 fold or more decrease in their electrical resistivity, even at concentrations of $0.005 \mathrm{wt} \%$ [32]. The electrical field distribution of both conventional electrochemotherapy and nsPEF applications to solid tumors is dependent upon the size and the histology of the tumor. Solid tumors are very heterogeneous, from tumor type to tumor type, and from individual to individual. This heterogeneity makes it difficult to predict how an electrical field application will pass through the tumor [33, 34]; therefore, the expected biological effects may be extremely variable. The use of CNTs to distribute electrical fields has promising potential [35]; and although MacDonald 2008 [31] has shown that electrical conductivity in fibroblast seeded hydrogels are markedly increased, there is no information relating to increased conductivity in tumor models. To determine that cells exposed to nsPEF in the presence of MWCNTs have increased capacity to eliminate cancer cells, experiments were performed exposing PANC1 cells grown in the presence of MWCNT to eight $50 \mathrm{kV} / \mathrm{cm}$ pulses of $300 \mathrm{~ns}$ duration. $140 \mu \mathrm{l}$ of sample was loaded into a cuvette with two parallel plate electrodes with an electrode area large compared to the distance between electrodes (1mm). Energy density was $75.4 \mathrm{~J} / \mathrm{cm}^{3}$ per pulse. (Detailed in [25]) Cell viability, as measured by trypan blue uptake, was normalized against unexposed cells (Figure 5). 
Cells grown in the presence of T80 and MWCNTs showed viabilities of 94.6+/- 3.5\% and 92.9+/-5.0\%, respectively, showing that these agents alone are not toxic. There was no significant difference $(\mathrm{p}=0.24)$ in cell viability when PANC1 cells were exposed to eight $300 \mathrm{~ns}$ pulses compared to cells pulsed in the presence of $0.002 \%$ T80 (73.6+/-6.1\% and 63.9+/-10.5\% respectively). Cells grown in the presence of MWCNTs and then pulsed (31.5+/-9.8\% viability) under the same conditions showed a significant difference in viability compared to nsPEF exposed controls in the absence $(p=0.003)$ or presence $(p=0.02)$ of $T 80$. The reduction in significance between MWCNT nsPEF exposed cells and T80 nsPEF exposed cells shows that T80 clearly has a synergistic role in the viability of exposed cells, possibly through interaction with the lipid cell membrane. T80 is a surfactant that is commonly used as a food additive and has clinical applications; therefore its use in conjunction with nsPEF applications is a distinct possibility. Thus, cells grown in the presence of MWCNTs and exposed to high-energy pulsed electrical fields show decreased viability. These preliminary experiments agree with the hypothesis that MWCNT may be increasing energy dissipation, reducing cell viability.

This study demonstrates that ultrashort pulse electrical field applications have enhanced effects when cells are previously grown in the presence of MWCNTs, suggesting the electrical properties of MWCNTs play a vital role in this process and is suggestive of a synergistic interaction between these nanomaterials and electrical fields. The efficacy of 300nsPEF treatment applications to small (3-4mm) B16 derived skin melanomas in mice have been described [36], where complete remission was reported. The electric field distribution across small tumors is less problematic than larger tumors where a greater degree of inter-tumor and inter-individual variation exists. The use of MWCNTs in producing a more uniform electric field across a larger tumor would aid in predicting biological and treatment outcomes. The toxicity of MWCNTs has been the attention of much debate, with conflicting reports [23, 37]. Reports describing invalid results with carbon nanotubes when toxicity is measured by dye-based assays, such as the MTT assay [38], led us to use the trypan blue exclusion method, which is a stain that is excluded in live cells but taken up by dead cells, giving them a blue appearance [39] and is used as the basis of numerous toxicity studies. The trypan blue assay has been described to underestimate cellular toxicity [40]; therefore, our results can be considered to be conservative estimates and may explain the increase in cell numbers observed in HeLa cells compared to PANC1 cells. This is the first report measuring the toxicity of MWCNTs on PANC1 cells and 
shows that, although not statistically significant, there is a $40 \%$ reduction in population doubling in these cells, suggesting a slight toxic effect. Our results showing little toxicity in HeLa cells are in agreement with Yehia et al [41], although their results use single-walled CNTs rather than the MWCNTs described in our experiments. MWCNTs are considered to be less toxic than single-walled carbon nanotubes [42]. There are no reports on the toxicity of MWCNTs on B16 cells; however, the use of SWCNTs to carry small interfering RNA (siRNA) to modify dendritic cells and, thus, be able to reduce the growth of B16 melanoma cells through immunologic mechanisms have been described [43]. We have observed that the proportion of cells that have doubled when grown in the presence of MWCNTs appears to be cell-type specific; with the pancreatic cancer cell line PANC1 showing the greatest reduction compared to B16 and HeLa cells. Since the same MWCNTs preparation was used throughout the experiments, differences in MWCNTs preparations do not account for differences in the observed population doubling times. It is possible that the cell lines studied here each react differently to this type of MWCNTs, a concept that may be of importance in respect to use of MWCNTs in cancer treatment. Interestingly, pancreatic cancer has a poor prognosis, and very few successful and reliable treatments for this cancer type exist. We plan to perform experiments to confirm the localization of the MWCNTs in each cell type by atomic force microscopy with Raman spectroscopy. Applications of this technology in vivo will require the addition of functional groups to the MWCNTs to target specific cell types. The addition of functional groups has been described [44], however, functional groups are attached to the outer wall only which does not interfere with the electrical properties of the inner walls. We therefore expect that the electrical properties of functionalized MWCNTs will not be significantly diminished.

Our observations that PANC1 cells additionally are sensitive to ultrashort pulsed electrical fields, with a further 2.3-fold reduction in cell viability compared to pulsed control cells, is of considerable interest. A two-fold increase in apoptosis has been reported in PANC1 cells upon inhibition of selected kinases [45]. An increase in the induction of apoptosis as a cause of reduction in cell viability is a strong possibility and warrants further investigation. The same authors also report that chemotherapeutic agents are ineffective with pancreatic adenocarcinoma because this cancer is resistant to apoptosis induction. Targeting of pancreatic cancer cells with MWCNTs along with application of pulsed electrical fields may have potential as a future treatment modality. Successful treatment of a basal cell carcinoma has recently been 
reported using 12ns pulse electrical fields [46], and the use of pulse electrical fields in electrochemotherapy has undergone clinical trials [47]. This is the first report exploiting the electrical properties of MWCNTs in conjunction with pulse electrical fields to achieve increased cell death.

\section{Conclusions}

The fabrication of a pure sample of MWCNTs is described, and preliminary data have successfully demonstrated the feasibility of utilizing the electrical properties of carbon nanotubes with pulsed electrical field applications to achieve synergistic cell death. Pulsed electrical field applications are becoming increasingly common in cancer treatment, and the use of carbon nanotubes as a biomaterial to facilitate cell death is an important addition to this field. We plan to investigate improved electrical field distribution in solid tumors when using this biomaterial.

\section{Acknowledgements}

Drs. Elsayed-Ali and Osgood acknowledge National Science Foundation support from NIRT grant NSF-0507036. This work was partially funded by a grant from Old Dominion University Research Foundation, Norfolk, VA, and from the Breeden Adams Foundation, Norfolk, VA.

\section{References}

[1] Iijima S 1991 Nature 354 56-8

[2] Dai H, Hafner J H, Rinzler A G, Colbert D J and Smalley R E, 1996 Nature 384 147-50

[3] Choi W B, Chung D S, Kang J H, Kim H Y, Jin Y W, Han I T, Lee Y H, Jung J E, Lee N S, Park G S and Kim J M 1999 Appl. Phys. Lett. 75 3129-31

[4] Liu C, Fan Y Y, Liu M , Cong H T, Cheng H M and Dresselhaus M S 1999 Science 286 1127-29

[5] de Pablo P J, Graugnard E, Walsh B, Andres R P, Datta S and Reifenberger R 1999 Appl. Phy.s Lett. 74 323-5

[6] Wei Y Y and Gyula E, 2000 Appl. Phys. Lett. 76 3759-61

[7] Abdel-Fattah T M, Siochi E and Crooks R 2006 Fullerenes Nanotubes Carbon Nanostruct. $14585-94$ 
[8] MacDonald R A, Laurenzi B F, Viswanathan G, Ajayan P M and Stegemann J P 2005 J. Biomed. Mater. Res. Pt. A 74A 489-96

[9] Rege K, Raravikar N R, Kim D Y, Schadler L S, Ajayan P M and J.S. Dordick J S 2003 Nano. Lett. 3 829-32

[10] Kostarelos K, Lacerda L, Partidos C D, Prato M, and Blanco A 2005 J. Drug. Deliv. Sci. Technol. 15 41-7

[11] Singh R, Pantarotto D, McCarthy D, Chaloin O, Hoebeke J, Partidos C D, Briand J P, Prato M, Bianco A and Kostarelos K 2005 J. Am. Chem. Soc. 127 4388-96

[12] S. Kang, M. Herzberg, D.F. Rodrigues and M. Elimelech Langmuir 200824 6409-13

[13] Heller L C, Ugen K and Heller R 2005 Expert Opin. Drug. Deliv. 2 255-68

[14] Schoenbach K H, Beebe S J and Buescher E S 2001 J Bioelectromagnetics 22 440-48

[15] Beebe S J, Fox P M, Rec L J, Somers K, Stark R H and Schoenbach K H 2002 IEEE Trans. Plasma Sci. 30 286-92

[16] Beebe S J, Fox P M, Rec L J, Willis L K and Schoenbach K H 2003 FASEB J 171493

[17] Buescher E S and Schoenbach K H 2003 IEEE Trans. Dielectr. Electr. Insul. 10 788-94

[18] White J A, Blackmore P F, Schoenbach K H and Beebe S J 2004 J. Biol. Chem. 279 2296472

[19] Vernier P T, Sun Y, Marcu L, Salemi S, Craft C M and Gunderson M A 2003 BBRC 310 286-95

[20] Stacey M, Stickly J, Fox P, Statler V, Schoenbach K, Beebe S and Buescher S 2003 Mutation Research 542 65-75

[21] Hair P S, Schoenbach K H and Buescher E S 2003 J. Bioelectrochemistry 61 65-72

[22] Jodin L, Dupuis A, Rouviere E and Reiss P 2006 J. Phys. Chem. B 110 7328-33

[23] Wick P, Manser P, Limbach L K, Dettlaff-Weglikowska U, Krumeich F, Roth S, Stark W J and Bruinink A 2007 Toxicol. Lett. 168 121-31.

[24] Yehia H N, Draper R K, Mikoryak C, Walker E K, Bajaj P, Musselman I H, Daigrepont M C, Dieckmann G R and Pantano P 2007, J Nanobiotechnol. 23 5-8

[25] Schoenbach K, Hargrave B, Joshi R, Kolb J, Nuccitelli R, Osgood C, Pakhomov A, Stacey M, Swanson J, White J, Xiao S, Zhang J, Beebe S, Blackmore R and Buescher S 2007 IEEE Trans. Dielectr. Electr. Insul. 14 1088-1108

[26] Avetik R. Harutyunyan, Bhabendra K. Pradhan, Jiping Chang, Gugang Chen, and 
Peter C. Eklund, J. Phys. Chem. B 2002, 106, 8671-8675.

[27] Cheol-Min Yang, Hirofumi Kanoh, Katsumi Kaneko, Masako Yudasaka, and

Sumio Iijima, J. Phys. Chem. B 2002, 106, 8994-8999.

[28] Brian J. Landi,Cory D. Cress, Chris M. Evans, and Ryne P. Raffaelle, Chem. Mater. 2005, $17,6819-6834$.

[29] Li Wei, Bo Wang, Qiang Wang, Lain-Jong Li, Yanhui Yang, and Yuan Chen, J. Phys. Chem. C 2008, 112, 17567-17575

[30] Gajdová M, Jakubovsky J, Války J. 1993. Food Chem. Toxicol. 31(3):183-90

[31] MacDonald RA, Voge CM, Kariolis M, Stegemann JP (2008). Acta Biomaterialia, doi:10.1016/j.actbio.2008.07.005

[32] Guo Z, Wood JA, Huszarik KL, Yan X, Docoslis A (2007). J. Nanosci. Nanotechnology. 7(12); 4322-4332

[33] Miklavcic D, Beravs K, Semrov D, Cemazar M, Demsar F, Sersa G. (1998). Biophysical J. $74 ; 2152-2158$

[34] Miklavcic D, Corovic S, Pucihar G, Pavselj N. (2006). European J. Cancer (supplement). 4; $45-51$

[35] Dekker C. (1999). Physics Today.May. 22-28

[36] Nuccitelli R, Chen X, Pakhomov AG, Baldwin WH, Sheikh S, Pomicter JL, Ren W, Osgood C, Swanson RJ, Kolb JF, Beebe SJ, Schoenbach KH. (2009) Int J Cancer. 15;125(2):438-45

[37] Monteiro-Riviere N A and Inman A O 2006 Carbon 44 1070-8

[38] Monteiro-Riviere N A, Inman A O and Zhang L W 2008 Toxicol. Appl. Pharmacol. ePub.2008

[39] Strober W 2001 Current Protocols in Immunology May Appendix 3

[40] Fellows M D and O’Donovan M R 2007 Mutagenesis 22 275-80

[41] Yehia H N, Draper R K, Mikoryak C, Walker E K, Bajaj P, Musselman I H, Daigrepont M C, Dieckmann G R and Pantano P 2007 J. Nanobiotechnol. 5:8doi:10.1186/1477-31555-8

[42] Jia G, Wang H, Yan L, Wang X, Pei R, Yan T, Zhao Y and Guo X 2005 Environ. Sci. Technol. 39 1378-83

[43] Yang R, Yang X, Zhang Z, Zhang Y, Wang S, Cai Z, Jia Y, Ma Y, Zheng C, Lu Y, Roden R and Chen Y 2006 Gene Ther. 13 1714-23 
[44] L Yu, C M Li, Q Zhou, Y Gan and Q L Bao 2007 Nanotechnology 18 115614. doi: 10.1088/0957-4484/18/11/115614

[45] Giroux V, Iovanna J and Dagorn J C 2006 FASEB J 20 1982-91

[46] Garon E, Sawcer D, Vernier T, Tang T, Sun Y, Marcu M, Gunderson M and Koeffler P 2007 Int. J. Cancer 121 675-82

[47] Heller R, Jaroszeski M J, Glass L F, Messina J L, Rapaport D P, DeConti R C, Fenske N A, Gilbert R A, Mir L M and Reintgen D S 1996 Cancer 77 964-71 


\section{Figure Legends}

Figure 1 shows a schematic of charge build-up following an nsPEF application to cells.

Figure 2. A high resolution TEM image and EDS analysis of MWCNTs used in this study (scale bar 200nm). The average diameter of MWCNTs is $15 \mathrm{~nm}$.

Figure 3. TGA curves (a) and corresponding DTGA curves (b) of the carbon nanotubes used in this study.

Figure 4. PANC 1 cell viability when cells are grown in the presence of T80 (\%) in growth medium.

Figure 5. Decreased viability of 300ns pulsed PANC 1 cells when pretreated with MWCNTs $(n=3+/-S D)$. 